Article:

\title{
Regional social planning for childhood in Italy
}

by

Giuseppe Moro

Professor of Sociology

Department of Education, Psychology and Communication University of Bari 


\section{Abstract}

The objective of the study is that of a planning document analysis of social and health-care policies developed by Italian regional governments during the period from 2007-2010, in order to identify a context analysis, objectives, actions relating to children and to verify the presence of an orientation to child's rights.

The document analysis concerning regional programmes for children was conducted employing a programme theory approach. This approach is used in order to compare programmes that, while very different in breadth and general scope, are nevertheless intervention plans for children, with the purpose of identifying the presence of common models and classifying any resulting differences.

Despite an overall framework that recognizes and protects the basic rights of children, the article concludes that in the documents analysed the most obvious limitation is represented by the difficulty with which a change of perspective is implemented in planning policies and services. Such a change leads to the consideration of children as not only recipients of a policy, but also as individuals with their own subjectivity and self-determination proportionate to the different stages of their development, who should therefore be granted the right to participate in the planning, implementation and evaluation of projects as they see fit. There is also a sense that programmes and services are primarily designed according to a process of "damage limitation", which is a result of the development of children as models of social organization that either cannot or do not want to change in order to promote the full recognition of the rights of children.

\section{Introduction}

The question of child protection emerged as a significant issue in Italy during the post-war period. It is therefore reasonable that in a poor country, with many thousands of children deprived of one or both parents, needy children were frequently entrusted to either national public institutions or those run by religious organizations. During the 1960s, growing doubts were raised among scholars and social workers relating to such institutionalization, along with numerous questions on 
the need to identify solutions for the most pressing issues of childhood on a relational level. During the 1970s, this led to the suppression of large national institutions and the reform of institutions of religious origin, alongside a move towards developing expertise in social policies (and therefore, also child protection) within both regions and municipalities. This would give way to experimentation of solutions considered innovative in Italy during the period, including kindergartens, nursery schools, regional centres for leisure and cultural promotion, psycho-pedagogical consultation centres, family planning clinics, housing and services for single mothers, home care for families and residential communities for children and young people. This phase of testing was institutionalized by Law 184 of 1983, which established the right of the child to a caring family structure, thus affirming the priority of interventions such as foster care, adoption, home care and the residential reception of children in small community groups.

Over the past 20 years, the focus on child policies for has been greatly reduced. Indeed, the attention of policy makers has shifted towards developing emergencies, such as the elderly in a society witnessing a stark contrast between birth rates and a population ageing at an increasing rate. Furthermore, in Italy, as elsewhere in Europe, policies have been implemented in order to reduce social expenditures, as well as rationalize and increase the efficiency and control of the costs of social services provision.

Such transformations are embedded in a political and institutional context in which it is not possible to speak of a national welfare system, as significant internal differences exist which highlight the presence of differing regional patterns in relation to those factors that characterize policy, including reference values, needs, the recognition of rights, resources, political and social actors, institutional and organizational structures and professional cultures (Moro and Bertin, 2012). Such differences are the result of both long-term historical processes and a regional decentralization initiated in the early 1970s and implemented, in terms of social policies, in the absence of a national legal framework. The relevant law, while only coming into force in 2000, made it possible to initiate growth processes in terms of the quality of welfare, even in the most problematic regions. However, its introduction 
was somewhat late, with different programming and governance models already rooted within the various regional institutions. The result is the persistence of uneven welfare systems throughout the Italian regions, a difference that in many respects reflects the distinction between the most economically developed central and northern regions and the regions of the poorer south. The central-northern regions are therefore characterized by generalized and generous welfare systems, while minimal and unstructured welfare systems prevail in the south.

\section{Objectives of the study and theoretical framework}

The objective of the present study is that of a planning document analysis of social and health-care policies developed by Italian regional governments during the period from 2007-2010, in order to identify a context analysis, objectives, actions relating to children, and to verify the presence of an orientation to child's rights. As outlined above, the choice of analysing regional documentation stems from an awareness of the central importance of the regions at an institutional level in terms of the study of social programmes aimed at children.

The international comparative analysis of child protection systems reveals that, in addition to the two traditional models characterized by a child protection- or family service orientation (Gilbert, 1997), an alternative approach called "child-focused orientation" (Gilbert, Parton, and Kivenes, 2011) has emerged. While child protection systems are focused on the protection of a child from harm by relatives, and family service system's drive for intervention is the response to family unit needs, the third approach concentrates on the child as an individual, in which the object of concern is the child's overall development and well-being. As a consequence, programmes following the child-focused approach seek to go beyond protecting a child from risk to promoting children's welfare. The rationale of these policies is the perception of children as individuals something different from, but equally valuable, to adults. Children are seen as current rights-holder citizens, whereas the child-focused orientation puts children's rights above parental rights. 
The definition of child's rights can only be provided with reference to the now classic division, derived from the U.N. Convention for Children Rights of 1989, namely the rights of protection, provision and promotion.

The right to protection relates to the children's right to live and their protection from abuse, violence and neglect. Provision refers to the right to be born and grow up in good health, access to health services and social security and the right to education and play, while promotion embraces the rights of children as citizens, the right to be heard and participate, free expression and freedom of thought, religion and association.

The emergence of a child's rights approach in the social planning documents of the Italian regions may be an important innovation in a child protection system (and also in a welfare state) such as the Italian one, traditionally defined as "familistic", with a priority towards the dimension of social control that legitimizes the investments in childcare facilities strictly in terms of a reconciliation of work- and family life.

The document analysis concerning regional programmes for children was conducted employing a programme theory approach (Funnel and Rogers, 2011). In this case, this approach is not, used to identify the theory underlying a single programme or a group of similar programmes, but in order to compare programmes that, while very different in breadth and general scope, are nevertheless intervention plans for children, whose purpose is to identify the presence of common models and classify any resulting differences.

Hence, the work attempts to identify how such programmes seek to contribute towards generating a chain of intermediate results, and ultimately producing the desired results. The programme theory can therefore be developed by reconstructing the mental models of both the stakeholders and beneficiaries of policy interventions through interviews, through observing the implementation of the programme and through reconstructing the implicit theories of the various parties involved or, ultimately, as with the methodology employed in the present work, by analysing official policy documents in order to reconstruct the theories underpinning them. 
Programme theory should explain how planned activities will contribute to achieving the desired results, and can be divided into two categories: change theory and action theory. The first refers to the central process intended to produce the desired change for individuals, groups and communities, which in turn can be separated into three elements: the analysis of the situation, the focus (the identification of aspects of the issues on which the programme focuses as a priority) and the chain of outcomes (the relationship between the intermediate and final effects).

Action theory describes how programmes are designed to activate change, and fundamentally explains which activities will be undertaken in order to produce the desired end result. The basic components of action theory are the characteristics of the desired outcome or, rather, their attributes and criteria for the success of the internal or external factors that may influence the outcome and the programme tools, i.e. the resources, activities and products used in the implementation of the programme.

\section{Method of analysis}

The programme documents considered (see Appendix) to be essential belong to three categories: health or public health-care programmes, social programmes and service target action plans, 1 from which the sections specifically relating to interventions for the child were extracted.

The documents were independently read by three researchers using programme theory as scheme of interpretation; the models obtained were then compared to verify their concordance, and the inconsistencies were resolved through a discussion between the researchers.

The analysis through which the programme is documented (though often complex and confusing, and almost always produced through a juxtaposition of parts) may be related to that of a logic model, which undoubtedly involves the need to employ a certain forcing, yet has the advantage of allowing those causal process that policy

\footnotetext{
1 Within the 2007-13 European Union Structural Funds programme cycle, the Italian regions of the south and the islands are tasked with achieving the targets as agreed upon by national governments, with respect to a range of services (including nurseries), which are considered a fundamental part of the "Lisbon agenda".
} 
makers intend to activate to emerge with some clarity, so as to best be able to express evaluations on the quality of planning and the implementation design.

\section{Change theories of programmes}

\subsection{Reading the situation: Identifying the problem, its causes and consequences}

The most important aspects arising from the analysis of the condition of childhood contained within the regional documents are examined in the following section. In the interests of a clearer and more succinct examination, the description of the situation is provided in the form of a SWOT analysis, i.e. the strengths, weaknesses, opportunities and threats present within the framework of children. Weaknesses are identified on two levels: society and welfare structures.

On a social level, the focus is almost never placed on children alone, but instead is placed upon the wider context of family life. A background analysis is represented by changes in demographic structures, by a decline in birth rates and the ageing population, as well as those social realities at risk of deviance with respect to the modern notion of the nuclear family: large families and single-parent (female) families. Special attention is given within policy documents of the southern regions to the high rate of female unemployment, which to a large extent is due to the complex reconciliation between work and childcare. Children considered to be identified within those groups are considered to be particularly at risk such as, e.g. immigrants and minors experiencing removal protection orders from their biological family. For children belonging to "normal" family structures, attention is frequently focused on health risks such as lifestyles that may cause obesity, in addition to the increase in mental disorders as reported in the central-northern regions.

An indication of the weakness of welfare facilities dedicated to children is revealed as being both on a wide scale and highly diverse. An emerging feature common to all southern regions regards the imbalance between the demand by families for early childhood services, particularly nurseries, and their provision, whether public or private, along with the associated costs that result in being unsustainable for many families. Such a shortage in supply is even more greatly accentuated among those services seen as either alternatives to nurseries or logistical support, including play 
centres, play groups, home care, transport services for children and so on. The resulting social consequences are identified in the difficulties faced by women in terms of participation in the labour market. Moreover, welfare provision for children in the central-northern regions appears to be more highly consolidated, yet the difficulty of dealing with the needs of the new social phenomenon should not be underestimated such as, e.g. the number of immigrants and the need to ensure the widespread distribution of quality services. Furthermore, the established models of welfare emerge as often inappropriate in terms of extend fragmented and transient social relations and the weakening of traditional solidarity structures. Significant strength factors can therefore be divided into two groups.

The first consists of those elements that can be defined as social, referring to the ability of society and its institutional and relational systems to solve internal problems, particularly due to the notion of the family as retaining a central role in ensuring the growth processes of the young, as well as in improving community well-being (Regione Calabria, 2009; Regione del Veneto, 2010; Regione Valle D’Aosta, 2010).

The second set of strengths refers to the solidity and quality of welfare policies. A strong awareness exists in the central-northern regions of the benefits resulting from the presence of both the traditional system of social and educational services for children (nurseries), alongside an integrated personalized system (e.g. family and home educators) able to respond to support issues relating to care and the educational and cultural background of families. However, the effective presence of a regional network between institutions and the presence of non-profit organizations focused on childhood is revealed only in very few cases. Additionally, in the field of social services, it is of particular interest that documents in some southern regions, which are traditionally weak in welfare provision, report a contrary tendency over recent years in terms of the increase in available places in nursery schools, as well as a growing ability to meet the new needs of families by providing, for example, more flexible services.

What are the threats that may contribute to accentuating the features of the critical condition of childhood and adolescence, and thus reduce the effectiveness of support 
programmes? In this case, it may be useful to distinguish between those threats posed by social dynamics and those that may be consequences of the contradictions of the political and organizational processes of welfare.

Emerging from several documents is the awareness that the global and national economic crisis of recent years has made the phenomena of individual insecurity and community fragmentation ever more acute, thereby increasing vulnerability and unbalancing protection networks against economic and social risk (Regione del Veneto, 2010). This scenario is reflected by the bleak reality of childhood with the manifest inadequacy of educational agencies and, in particular families, as well as the possibility of increasing patterns of deviant behaviour among children, thus diminishing the social perception of the severity of such behaviour (Regione Lombardia, 2010). The growth of the immigrant population also underscores an issue of concern in terms of its demographics (high number of children) and social and economic characteristics (poverty or hardship), hence ensuring an increased demand for social and educational services.

The increasingly complex relationship between supply and demand almost certainly represents one of the cornerstones of the perception by regions of impending difficulties. Indeed, it is stated in many documents that the most serious risk is represented by that arising from the gap between the strong increase in demand for social benefits (due to the crisis) and the subsequent pressure on services, and the lower overall availability of resources resulting from essential public spending cuts. Even those consolidated as more regional welfare systems mention the risk that staffing levels are insufficient to ensure the adequate quantity and quality of responses to existing needs, which is accentuated by an emotional overload on the part of operators (Regione Emilia Romagna, 2008).

The availability of resources arising from EU structural funds for the development of new services for children represents the greatest opportunity identified by, above all, those regions where the supply of such services has traditionally been below the national average. This may be added to the various national and regional legislative measures promoting and supporting interventions on behalf of children or 
innovatively regulating service delivery, such as equating public and private service standards. Furthermore, that same growth as far as the demand for services for children is considered an opportunity for economic development and the creation of new employment. Further opportunities are identified in the spread of the integration processes between social and health-care programming, the increase in community participation experiences in policy planning processes for children (Provincia autonoma di Trento, 2009) and in the increase of the possibility of international comparison that allows for an updating of intervention and prevention models (Regione Lombardia, 2010). A further opportunity is noted, on an even broader level, stemming from the emergence of a cultural vision of social programming that offers an integrated approach to interventions for the promotion of the family (Regione Piemonte, 2010).

In summary, in planning documents analysed the context analysis focuses primarily on the needs of children placed in problematic family contexts and the weakness factor prevalent in the southern regions with regard to an imbalance between the supply and demand of childcare services, whereas the central-northern regions are faced with the difficulty of responding to new types of need. While in the northern regions the presence of solid, quality welfare systems emerges as a strength factor, the threat arising across the country as a whole is represented by an increase in the demand for services due to the economic crisis in the context of the implementation of spending cuts in welfare provision. Lastly, the availability of EU structural funds and the emergence of integration between the different social policies frameworks are considered as opportunities.

\subsection{The focus of programmes}

The next step attempts to understand programme theory in terms of identifying those aspects considered as being of greater importance, and on which the programme is intended to primarily and directly intervene in order to modify them. A programme therefore generally attempts to pursue a number of general objectives and, in so doing, also determines its boundaries or, rather, those aspects in which the programme does not intend to intervene. 
The reading of the programmes highlights a high degree of homogeneity regarding the choice of the scope of an action, and thus the boundaries within which it attempts to operate.

Firstly, the child is almost never referred to as an individual in possession of those rights that society, and institutions in particular, have a duty to recognize and render effective. Moreover, attention should be placed on their insertion within stable or unstable relational networks (the family in its various forms and conditions) or as a social actor playing a role within institutions (especially schools). Consequently, objectives are predominantly directed towards securing the effective operation of such institutions and towards ensuring that the child conforms to appropriate institutional patterns of behaviour. A second, quite clearly defined boundary is represented by the preschool age group (0-6 years) in which the regions intend to intervene, while the 6-14 age group is almost never taken into account.

It could be argued that, by virtue of the system of compulsory education from 6-14 years of age currently in force in Italy, the actions of the state school would "deplete" institutional interventions, and that other programmes could be useful only in terms of educational support. Children between the ages of 6-14 fall within the scope of regional policies only when digressing from "normality" (those with disabilities, serious illnesses or mental disorders of a greater or lesser severity) when escaping institutional constraints (specifically school dropouts) or, lastly, when their families are unable to effectively carry out their educational and protective functions.

A final clearly defined boundary concerns the threshold for the effectiveness of the programme; such actions almost never attempt to change the economic, social and cultural development conditions that may have originally generated the social problems with which they are confronted. The function of welfare is therefore reparative in nature; given certain external conditions which are not considered as changeable, programme interventions aim to reduce those consequential social effects considered as being negative. 
The objectives that regional programmes intend to achieve may be considered as belonging to two main categories: one relating to services and their proper functioning, the other relating to those individuals or families wishing to change or improve their conduct or competencies.

With regard to the objectives relating to services for children and their families, the regions can be divided into two groups: one comprising almost all regions of the south with a welfare system defined as minimal and poorly structured, the other primarily comprising those regions located in the centre-north. The objectives of the first group are quantitative. From a starting point of a lower capacity for provision with respect to the national average, the aim is that of increasing the percentage of municipalities with nurseries and children in the 0-3 age range who are able to benefit from such service provision. Another significant objective present in the documents of these regions is the strengthening of the so-called "spring sections" or, instead, pre-school classes that can be attended by children under three years of age, thereby allowing for the transition between nursery and infant school. In line with the aim of increasing the provision and use of infancy services, objectives for rendering the system more flexible are provided, hence overcoming the distinction between public and private services and supporting demand through a voucher system for low-income families.

It is of interest to note that such operational objectives are, for the most part, included within the general aims referring to the need to allow women to reconcile work with family care, thus promoting the economic development of the local area and contrasting the tendency of declining birth rates. In only a very limited number of cases is the expansion of nursery provision associated with «the right of the child to live in more acceptable conditions from an educational, environmental, social and cultural viewpoint, safeguarding psychophysical development» (Regione Calabria, 2008):

91 ) or the conviction that «children services should be conceived not only as a support for parents but also as an investment for the social development of children themselves» (Regione Abruzzo, 2008a: 66). 
In regions with more established welfare systems in terms of the provision of nursery services in the area, dominant issues include those of quality enhancement and innovation. The issue of quality refers to the objective of a more standardized provision throughout the area, aligning it to demonstrated best practices and the need to offer more responsive services to the real needs of families. In essence, innovation would appear to refer to the promotion and strengthening of networks between different service providers, and especially between public institutions and civil society. Indeed, in documents of these regions, the child and his or her rights are not the focus of policy, but attention is instead primarily focused on the need to reconcile the time occupied by childcare and work and the promotion of the more general "welfare of the community". A common and widespread operational objective throughout all regions is that of the promotion of foster care as a priority for the reception of children whose families are unable to exercise parental functions.

The reading of the objectives of outcomes or, rather, changing the behaviour and opportunities of the beneficiaries of a policy, makes the focus even more explicit for those programmes aimed at the family, or rather at parents, with a perspective that can be describe as "adult-centric". The general objectives of the most widespread programmes are the promotion of parenting education and support for the centrality of the family. Such objectives are targeted for situations considered to be at risk or, in any case, at least fragile, specifically the development of the autonomy of singleparent families, support to young families wanting to have children and the prevention of social risk through the promotion of skills and parenting duties and care.

\section{3 Theoretical patterns of change}

At the heart of change theories lies the identification of the chain or hierarchy of results, which highlights the hypothesized relationships existing between the immediate or intermediate and final results or impacts, both in the short and long term. The identification of the chain of results may help to clarify how those outcomes that the programme intends to achieve may assist in overcoming the issues that initially gave rise to the programme itself. 
Theories of individual programmes may be traced back to various general patterns of change based on research that constitute theoretical references, particularly for interventions aimed at children (Funnel and Rogers, 2011: 319-349).

At the level of individual change, a significant reference theory relates to that of rational action or planned behaviour (Ajzen and Fishbein, 1980; Fishbein and Ajzen, 2009), which is based on the assumption that humans are rational and have control over their actions.

A further change model is represented by the theory of empowerment (Perkins and Zimmerman, 1995) mainly employed for individuals, but which can also be applied to organizations, communities, societies and cultures, thereby emphasizing participation and self-determination. Empowerment is a process through which individuals achieve control and mastery over their lives and are able to influence those conditioning their existence in some way.

A third theory of reference is that of diffusion (Rogers, 1995), which argues that change occurs when new ideas are created, diffused, adopted or rejected. Diffusion is a process by which an innovation is communicated through certain channels at any one time to the members of a social system.

A fourth change model, widely adopted in recent years in theoretical reflections on social policy, is that of network theory (Granovetter, 1973; Davies, 2002; Keast and Brown, 2005). This theory states that the position of social actors in a set of relationships and their corresponding nature and type can promote or hinder the outcomes of a programme.

A final theory, which may be considered a particularly relevant change model for programmes aimed at children, is that of the ecological systems of Bronfenbrenner (1979). In this model, four systemic layers may be distinguished, one contained within the other: the exosystem, macrosystem, microsystem and mesosystem. The most significant concept of this theory is the existence of a close interdependence between the different layers, thus considering the development of the child as a 
process within which the child both changes its various environments, while also being influenced by those environments.

\subsection{The chains of results}

Which theories of change, whether expressed or implied, can therefore be identified by analysing regional documents, and on which of the models discussed above are they predominantly based?

A central role is bestowed within a group of programmes on the family, which in turn is also identified as the motor and purpose of such change. The family is considered the fundamental resource of the system and the centre around which policies and services revolve (Regione Lombardia, 2010; Regione Piemonte, 2010; Regione Valle D'Aosta, 2010). Social and health policies are therefore designed to support families as primary agents of socialization (Regione del Veneto, 2010), as well as support services which should aim to improve the educative actions of the family (Regione Calabria, 2009). The theoretical model of such policies seems to relate to empowerment: families possess the resources to deal with their problems, including education, and policies must rediscover and enhance them in order to promote the growth of solidarity and prevent or combat risk. Children are the immediate direct beneficiaries of the development of families inasmuch as the latter is able to exercise with greater competence the educational actions of which they are the recipients. A further causal chain is thus configured, linking the centrality of the family to the integration of various social and health-care policies. Although the direction of causality is not well identified, it is believed that the focus of policies and interventions in the family (and not its individual components or specific challenges) generates a reorganization of service provision towards integration. In comparison to the theoretical model of empowerment, references to the active role of families in the design of those policies addressed to them are absent, with highly unstable references to the spaces of participation and control that users should/could have in the management and delivery of services.

The approach to change appears to be more systemic in other programmes. For example, reference is made to the worlds of everyday life (a sociological concept 
inspired by phenomenology) and their relationships as the most important contexts for the development of children, or it is stated that «child protection, both as a legal defence and in terms of promoting social well-being, is a task to be carried out in collaboration between families, schools and services in order to promote the harmonious growth of the child and the development of a culture of the rights of the child» (Regione Emilia Romagna, 2008: 68). In comparison to the model of Bronfenbrenner, there is either the total absence- or a significant lack of references made to wider spheres within the ecological system and to the conditioning that they can exert on the resources of families, even those made available through the intervention of services.

According to a simplified model of rational action, the presence of a deterministic concept of change generated by the programmes is particularly evident in the action plans for the creation of nursery schools (Regione Abruzzo, 2008a; Regione Calabria, 2008; Regione Molise, 2009b; Regione Puglia, 2009a; Regione Siciliana, 2008). In this case, the chain of results is defined and standardized, as it is assumed that the increase of the provision of nursery places, supported in only a few cases by a financial contribution to lower income families that allows for the reconciliation of work and childcare, pushes women towards insertion into the labour market and the resulting increase in the competitiveness of the region. In comparison to the rational choice model, it would appear that such a model does not sufficiently take into account the beliefs, values, perceptions and preference systems of women and their families, and could lead to a lack of uptake of an increase in provision. Similarly, it does not stimulate active inclusion into the labour market, particularly as it occurs in southern regions where action plans are implemented, when it does not provide new jobs or otherwise create opportunities that can lead women towards changing their overall preference framework.

In summary, the change theories in the regional programmes analysed are structured, more or less intentionally, according to two prevailing models: rational action and empowerment. 
The first assumes that the behaviour of individuals may be modified by adapting their range of opportunities through an increase in the provision of services of various kinds; the causal chain is structured in such a way that this provision is primarily directed towards adult subjects in order to improve their social skills, and it is therefore assumed that such a change will have intermediate effects on children by decreasing deviant behaviour or the likelihood of experiencing situations of risk or hardship.

However, programmes that assume the theory of empowerment as their model point towards locating and utilizing the various kinds of resources already in the possession of those social subjects for whom the programmes are intended to trigger self-directed change processes in the direction of acceptable behaviour and social attitudes, which may prevent social risks for the child.

Theories of change that refer to concepts considered crucial in various interpretations of contemporary society in relation to the network and diffusion of innovation as it passes through the various forms of communication appear to be either absent or highly unstable. Reference to network programming documents relates to the network of services (public and private) that should be promoted in order to increase the integration of policies, yet reference is almost never made to the social networks to which children and their families belong and to the problems and potential that such networks are able to express. Similarly, there would appear to be little awareness of the communicative forms through which innovation and change may be developed, a significant oversight in an age in which the values, attitudes and behaviour of children are strongly influenced by means of mass communication and the use of the electronic networks.

\section{Action theories and tools for implementation}

Action theory consists of the choices that a programme will make in order to achieve its objectives and thus enable change.

With regard to the analysis of regional planning documents, the focus should be placed on a specific aspect of action theory, i.e. the mechanisms identified to activate 
change. Indeed, the identification of such mechanisms allows for a summary identifying the homogeneous or inhomogeneous forms of implementation.

\subsection{Programme archetypes}

Five programme archetypes, or categories of interventions aimed at activating mechanisms of change, can be identified in the literature (Funnel and Rogers, 2011: 351-386).

The first archetype refers to those programmes that aim to activate change by means of a change in the attitudes, knowledge and skills of the target groups using tools such as advice, information and education, measuring results on the basis of what recipients have learned, on the appropriate change in their attitudes and interests and on the information which they have been successful in conveying (Kirkpatrick, 1998).

The second pattern is composed of programmes known as the "carrot and stick" (Bemelmans-Videc et al., 1998), which seek to influence behaviour through the use of incentives in order to reward positive behaviour and/or penalties or threats discouraging behaviour considered to be negative.

The third category is composed of case management programmes, which consider each case as unique and therefore request ad hoc processes in order to change behaviour, and produce intermediate and final results that cannot be defined in standard ways (St. Pierre et al., 1999).

The fourth model is provided by those programmes involved in the promotion of capacity building in the community or, rather, the activation of a non-predefined process through which a community can develop a better understanding of the issues, opportunities and challenges that concern them, increase knowledge and awareness of their own skills and the resources they possess in order to face new opportunities and meet challenges, and identify, plan and implement activities and processes in order to improve opportunities, thereby increasing and safeguarding their well-being (Kretzmann and McKight, 1993). 
The fifth pattern is formed through the provision of direct services or products and the notion that the behaviour of target groups is modified using services and products in a manner considered appropriate by the programme designer.

\subsection{Tools of implementation}

The most frequently proposed tool for achieving the objectives as contained within regional planning documents is represented by the direct provision of services and products. Those services most often mentioned relate to supporting families in terms of the care, education or, more simply, the custody of children through nursery schools, "spring sections", play centres and playschools and other similar structures. Nonetheless, for children faced with conditions of particular hardship and neglect, tools are preferred that are able to in some way reproduce the institution of the family, such as foster homes. The choice favouring the family as a tool and model for social intervention is evident in the provision of home help support and its caring and educative role (educational home help, home care support, etc.), and especially in the proposal of foster care. Indeed, foster care is almost universally considered the most effective means of ensuring care and educational support to children at risk within their biological family, with specific foster care services planned both in terms of general and economic support (professional foster care).

There is widespread agreement concerning service delivery methods on the broadening and highly flexible supply of services through the accreditation of services managed by private and third sectors organizations, as well as their inclusion in the public system. The decision to support requests through monetary incentives was also identified in some regional documentation.

The importance and dissemination of the implementation model for social policies centred on services is confirmed through reference, albeit infrequent and often mechanical, to methods of programme evaluation. The evaluation criteria for the achievement of output targets are almost always highlighted, such as the number of services carried out or the number of users and their relationship to the target population, hence clearly referring to the processes of service delivery. However, references to evaluation models that take the involvement and opinion of the various stakeholders into account, and that are aimed at their empowerment, are absent. 
Although the most widely used implementation tool is represented by the direct provision of services, an important distinction should be made between those regions defined by their poorly structured or minimal welfare provision and others with more generalized and consolidated systems.

Particular attention to the expansion of services can be specifically identified in the programming of those regions with the historically weakest welfare systems. Through the use of European and central government funds, these regions intend to reduce the gap in the national average, thus confirming the positive dynamics that characterize the social policies of some regions in the south. The use of incentives is also occasionally included within their programming in order to promote the use of services among lower income families.

In regions where the supply of services is broader, with an established competence in responding to at least the basic needs, an expanded range of tools is employed and greater differences emerge in terms of the choice of implementation tools.

Some regions, mostly governed by centre-right political majorities, envisage the generalization of the use of vouchers in support of expenditures incurred by households for the development, nurturing, education, socialization and access to children services, regardless of the public or private nature of the supplier of such services (Regione Lombardia, 2010).

Other regions, mostly of a centre-left political orientation, seem closer to the model defined as capacity building, with an emphasis placed on interventions for strengthening parental skills and supporting family relationships by undertaking counselling and parental and educational counselling (Regione Emilia Romagna, 2009).

The use of policy tools such as training and information is both more transversal and widespread, yet is nearly always addressed to specific recipients such as social workers, health-care workers and educators and, less frequently, parents. It is assumed that the development of their skills, promoted through participation in 
training activities, will have a positive outcome on the effectiveness of their educational actions aimed at children.

In summary, the predominant implementation tool is represented by the activation of services (whether publicly or third-sector managed) that produce support actions for families or familial structures for the reception of those minors who cannot be cared for- or educated by their biological families. It is also possible to identify capacity building programmes aimed at families and training interventions principally geared towards operators in social and educational service provision.

\section{Conclusions: Regional programming and the right of the child}

It is necessary to emphasize that the analysis conducted thus far is related to the planning documents of various Italian regions and not to the implementation of welfare policies and the social impact that such policies generate. However, theoretical constructs have been examined in the present work that reveal not only ideal visions of society and policy goals, but also of models and interpretations of regional contexts and existing social issues.

While exercising caution, it is nevertheless necessary to investigate the attention devoted by programmes to focusing on the rights of children and, above all, which rights are recognized and promoted, and which are overlooked.

The main focus in the programming of Italian regions is certainly related to rights of provision. Most objectives and tools are aimed at ensuring that children are granted access to quality social and health-care services, an adequate educational system in order to counteract the phenomena of dispersion and spaces for play and creativity. An attentive analysis of the documents, particularly those sections concerning the analysis of the present situation, reveals that in many regions (especially those in the centre-north) the protection and promotion of such rights already extends to most of the population and ensures high standards. However, while the conditions of southern regions initially appear far less positive, it should be noted that the programming of such regions is resolutely directed towards a process of change involving the investment of significant resources. 
Less of an emphasis is placed on the rights of protection, perhaps due to the unsupported belief that such needs relate to a smaller number of children. Nonetheless, it should be underscored that the establishment of a primary protection network falls within the objectives of the plans of all regions, as confirmed by the presence of child protection centres and emergency shelters, as well as the relatively widespread programming of information and training activities on the theme of violence against children. Even so, the issue of child labour has largely been ignored. Indeed, the issue affects numerous Italian children living in many areas of the southern regions, in addition to a large proportion of immigrant children across the country as a whole.

The most significant limitations are identified in the recognition of the rights of promotion. It is possible to observe how the design of services is almost exclusively centred on the needs of adults and "society", and that only occasionally is attention paid to the "voice" of children in the design of childcare, while never referring to the right of the child to be heard and involved in those decisions that concern them.

Despite an overall framework that recognizes and protects the basic rights of children, it can therefore be concluded that the most obvious limitation is represented by the difficulty with which a change of perspective is implemented in planning policies and services. Such change leads to the consideration of children as not only recipients of a policy, but also as individuals with their own subjectivity and selfdetermination proportionate to the different stages of their development, who should therefore be granted the right to participate in the planning, implementation and evaluation of projects as they see fit. There is also a sense that programmes and services are primarily designed according to a process of "damage limitation", resulting from the development of children as models of social organization that either cannot or do not want to change in order to promote the full recognition of the rights of children.

References to the rights of participation are either weak or entirely absent within the programming documents analysed, a factor that may render policies aimed at the promotion of other rights less effective. Indeed, the distinction between types of rights 
may be useful from an analytical point of view, yet from a perspective of unity and dignity of the child, the promotion of human rights is fully effective only when unitary and integral. 


\section{Appendix: List of the planning documents analysed.}

(The documents can be retrieved in the databases of the "Istituto degli Innocenti" of Florence: www.biblioteca.istitutodeglinnocenti.it)

1. Provincia autonoma di Bolzano (2007). Piano sociale provinciale 20072009.

2. Provincia autonoma di Trento (2009). Linee guida per i piani giovani di zona e di ambito.

3. Regione Abruzzo (2008a). Piano d'azione per gli obiettivi di servizio 20072013.

4. Regione Abruzzo (2008b). Piano straordinario per lo sviluppo dei servizi socio-educativi della prima infanzia.

5. Regione Basilicata (2012). Piano regionale integrato della salute e dei servizi alla persona e alla comunità 2012-15.

6. Regione Calabria (2008). Piano d'azione regionale per il raggiungimento degli obiettivi di servizio.

7. Regione Calabria (2009). Piano regionale degli interventi e dei servizi sociali e indirizzi per la definizione dei Piani di zona - Triennio 2007-2009.

8. Regione Campania (2009). Piano sociale regionale 2009-2011.

9. Regione Emilia Romagna (2008). Piano sociale e sanitario 2008-2010.

10. Regione Emilia Romagna (2009). Piano regionale per la promozione e tutela dei diritti, la protezione e lo sviluppo dei soggetti in età evolutiva e il sostegno alla genitorialità.

11. Regione autonoma Friuli Venezia Giulia (2010). Piano sanitario e sociosanitario 2010-2012.

12. Regione Lazio (2009). Piano sanitario regionale 2010-2012.

13. Regione Lombardia (2010). Piano socio-sanitario regionale 2010-2014.

14. Regione Liguria (2009). Piano socio-sanitario regionale 2009-2011.

15. Regione Marche (2009). Approvazione delle linee guida per la predisposizione e approvazione dei piani triennali di ambito sociale 20102012.

16. Regione Molise (2009a). Piano sociale regionale 2009-2011.

17. Regione Molise (2009b). Piano d'azione per il raggiungimento degli obiettivi di servizio 2007-2013. 
18. Regione Piemonte (2010). Piano triennale 2010-2012 degli interventi e dei servizi sociali.

19. Regione Puglia (2009a). Piano d'azione per il raggiungimento degli obiettivi di servizio 2007-2013.

20. Regione Puglia (2009b). Piano regionale delle politiche sociali 2009-2011.

21. Regione Siciliana (2008). Piano d'azione degli obiettivi di servizio del Q.S.N. 2007-2013.

22. Regione del Veneto (2010). Piano regionale Infanzia, Adolescenza, Famiglia.

23. Regione Valle D’Aosta (2010). Piano regionale per la salute e il benessere sociale. 


\section{References}

Ajzen, I., \& Fishbein, M. (1980). Understanding Attitudes and Predicting Social Behavior, Englewood Cliffs, New Jersey: Prentice Hall.

Bemelmans-Videc, M. L., Rist, R. C., \& Vedung, E. (1998). Carrots, Sticks and Sermons, New Brunswick, New Jersey: Transactions.

Bronfenbrenner, U. (1979). The Ecology of Human Development, Cambridge, Massachusetts: Harvard University Press,

Davies, R. (2002). "Improved Representation of Change Processes: Improved Theories of Change", Paper presented at the Fifth Biennial Conference of the European Evaluation Society, Seville.

Fishbein, M., \& Ajzen, I. (2009), Predicting and Changing Behavior: The Reasoned Action Approach, New York: Psychology Press.

Funnel, S. C., \& Rogers, P. J. (2011). Purposeful Programme Theory. Effective Use of Theories of Change and Logic Models, San Francisco, California: Jossey Bass.

Gilbert, N. (Ed.) (1997). Combatting child abuse: International perspectives and trends, New York: Oxford University Press.

Gilbert, N., Parton, N., \& Skivenes, M. (Eds.) (2011). Child protection systems: International trends and orientations, New York: Oxford University Press.

Granovetter, M. S. (1973). The Strength of Weak Ties, American Journal of Sociology, 78 (6), pp. 1360-1380.

Keast, R., \& Brown, K. (2005). "The Network Approach to Evaluation: Uncovering Patterns, Possibilities and Pitfalls", Paper presented at 2005 Australasian Evaluation Society International Conference, Brisbane. 
Kirkpatrick, D. L. (1998). Evaluating Training Programmes: The Four Levels, $\left(2^{\text {nd }}\right.$ ed.), San Francisco, California: Berret-Koehler.

Kretzmann, J. P., \& McKnight, J. L. (1993). Building Communities from the Inside Out: A Path Toward Finding and Mobilizing a Community's Assets, Evanston, Illinois: Institute for Policy Research.

Moro, G., \& Bertin, G. (2012). "I sistemi regionali di welfare in Italia". In I. Colozzi (Ed.), Dal vecchio al nuovo welfare. Percorsi di una morfogenesi, Milano: FrancoAngeli.

Perkins, D., \& Zimmerman, M. (1995). Empowerment Theory, Research and Application, American Journal of Community Psychology, 23(5), pp. 569-579.

Provincia autonoma di Trento (2009). Linee guida per i piani giovani di zona e di ambito.

Regione Abruzzo (2008a). Piano d'azione per gli obiettivi di servizio 2007-2013.

Regione Abruzzo (2008b). Piano straordinario per lo sviluppo dei servizi socioeducativi della prima infanzia.

Regione Calabria (2008). Piano d'azione regionale per il raggiungimento degli obiettivi di servizio.

Regione Calabria (2009). Piano regionale degli interventi e dei servizi sociali e indirizzi per la definizione dei Piani di zona - Triennio 2007-2009.

Regione Emilia Romagna (2008). Piano sociale e sanitario 2008-2010.

Regione Emilia Romagna (2009). Piano regionale per la promozione e tutela dei diritti, la protezione e lo sviluppo dei soggetti in età evolutiva e il sostegno alla genitorialità. 
Regione Lombardia (2010). Piano socio-sanitario regionale 2010-2014.

Regione Molise (2009b). Piano d'azione per il raggiungimento degli obiettivi di servizio 2007-2013.

Regione Piemonte (2010). Piano triennale 2010-2012 degli interventi e dei servizi sociali.

Regione Puglia (2009a). Piano d'azione per il raggiungimento degli obiettivi di servizio 2007-2013.

Regione Siciliana (2008). Piano d'azione degli obiettivi di servizio del Q.S.N. 20072013.

Regione del Veneto (2010). Piano regionale Infanzia, Adolescenza, Famiglia.

Regione Valle D'Aosta (2010). Piano regionale per la salute e il benessere sociale.

Rogers, E. (1995). Diffusion of innovation, New York: Free Press.

St. Pierre, R., Layzer, J., Goodson, B., \& Bernstein, L. (1999). The Effectiveness of Comprehensive Case Management Interventions: Evidence from National Evaluation of the Comprehensive Child Development Programme, American Journal of Evaluation, 20 (1), pp. 15-34. 